\section{OPEN ACCESS}

Edited by:

Gareth Dylan Smith, Boston University, United States

Reviewed by:

Matthew Clauhs,

Ithaca College, United States

Kelly Bylica,

Boston University, United States

*Correspondence:

Daniel Walzer

dawalzer@iu.edu

Specialty section:

This article was submitted to

Educational Psychology,

a section of the journal

Frontiers in Education

Received: 28 December 2020

Accepted: 22 March 2021

Published: 14 April 2021

Citation:

Walzer D (2021) Fostering Trauma-Informed and Eudaimonic

Pedagogy in Music Education.

Front. Educ. 6:647008.

doi: 10.3389/feduc.2021.647008

\title{
Fostering Trauma-Informed and Eudaimonic Pedagogy in Music Education
}

\section{Daniel Walzer*}

Department of Music and Arts Technology, Purdue School of Engineering and Technology, Indiana University-Purdue University Indianapolis, Indianapolis, IN, United States

The arts and entertainment sectors remain fragile because of the global pandemic. Unemployment, physical and emotional stress, social isolation, a loss of purpose, and a problematic future are just a sample of the ongoing traumas that music educators and practitioners experience under duress. As an inherently social activity, music-making becomes especially difficult when the threat of infection persists, further exacerbating somatic trauma and decreased health and wellness. The sudden loss of daily contact with others, coupled with multiple kinds of crises, complicates matters for educators. How does one flourish when their livelihood, personal connections, and sense of meaning-making disappear? Likewise, how ought the music educator navigate such uncertainty when teaching others? To address these issues, psychologists have often turned to Trauma-Informed Care (TIC), a collaborative model between the practitioner and client that recognizes and validates the impact of painful memories and experiences. This article advocates for a compassionate eudaimonic pedagogy model that prioritizes healing and self-care for teachers and students and cultivating an ethos of critical digital pedagogy - itself a form of eudaimonia. Drawing on Noddings' (1992, 1995, 2002) Philosophy of Care, the article concludes with suggestions on future connections between eudaimonia and music education.

Keywords: eudaimonia, music education, pedagogy, trauma informed care, philosophy of care

\section{INTRODUCTION}

There is a palpable sense of loss among musicians and artists in the wake of an unprecedented pandemic. It will take years to unearth the coronavirus's long-term effects on the arts sector, including loss of employment, stress on educators and families, and the more profound emotional grief caused by ongoing physical, personal, and financial uncertainty. Rothschild et al. (2020) analyzed more than 250 canceled or postponed live events during the first half of 2020 with revenue losses totaling into the billions, prompting some national promoters to donate future tickets to essential workers. Recovery from the coronavirus must account for the lingering mental health challenges triggered by multiple stressors, as one in five face depression and anxiety (Grover, 2020). Rightly, Smith (2020) argues that examining Aristotle's (1976, Tredennick, rev. translation) concept of eudaimonia, described as human flourishing, or a life well-lived, seems slightly misguided in the wake of such global suffering. 
Indeed, as Smith (2020) argues, there is a disconnect between the epic loss of human life because of coronavirus and one's desire to re-define human flourishing in the middle of a pandemic. There is a direct correlation between global tribulation and eudaimonia; both are process-oriented, incomplete, and require scrutiny with one's existence with others. Strife, in whatever form, brings about opportunities and setbacks. For musicians, global pandemics instantly remove performances and close interaction with others. Loss of performing opportunities leads to financial uncertainty. Also, the disappearance of gigs has trickle-down effects for educators tasked with training the next generation of performers, composers, recording engineers, and arts professionals.

Arts educators occupy a distinct space in university settings. If we accept Kincheloe's (2008) assertion that education is political, then cultivating a politics of hope while simultaneously dealing with grief, the unpredictability of technology, and newfound responsibilities as counselors for students complicates any discussion on the ethos of flourishing. Suppose the spaces we occupy as artists and creative beings collapse alongside the communities that nourish collaboration and music-making. How is an analysis of Aristotelian ethics going to prove useful during a pandemic?

In actuality, while platforms and presentation formats on eudaimonia changed because of the pandemic (Smith, 2020), the more profound issues on finding purpose, promoting inclusivity, and encouraging diverse perspectives through edited collections remain prescient (Smith and Silverman, 2020). Likewise, the varied ideas explored in this special issue connect with the notion that human beings need music and need each other to inculcate a sense of belonging and centeredness with the mind, body, and spirit. Suppose we accept that music brings people together. What happens when the very act of music-making is harmful to our health-experienced through the transmission of an airborne virus at proximity?

The most obvious answer to this question is that human beings experience a deep and profound sense of loss. We're remanded to being isolated, socially distanced, and confined to wearing masks in public. These are very safe and proper responses from a medical standpoint. What remains unknown is the more profound effects social isolation has on one's deeper identity and a sense of purpose. I advocate for creating multiple kinds of spaces; a space for educators and musicians to grieve and process, while simultaneously honing a eudaimonic pedagogy that dignifies the humanity of pursuing the arts and lifelong learning.

Throughout the article, I discuss trauma and the concept of loss, noting that grief is a delicate construct. Understanding that "loss" myriad financial, physical, emotional, and professional opportunities, I concentrate on the music educator's loss of personal meaning and lack of close interaction with students and peers and how this tension requires a re-evaluation of eudaimonia educational best practice. To articulate the broader impacts of loss, I aim to connect the effects of a music educator's trauma on the broader community of musicians, learners, and vested stakeholders. Though this article is not an explicit criticism of eudaimonia, I argue that we must carefully analyze the intentions of pursuing human flourishing when the very elements that make us human, particularly in musical settings, remain precarious and fluid. Indeed, people find novel ways to innovate-singing on balconies, producing virtual choirs and bands online, rehearsing in cars, teaching remotely, and developing networked technologies for performing over distant networks. These activities somewhat align with the eudaimonic concept of a life well lived-impressive given the circumstances.

The issue is whether there has been sufficient discussion on how music educators can express the trauma they experience (during and after pandemics) and whether such vulnerability is supported and validated. To further elucidate grief and music education, I turn to Trauma-Informed Care (TIC), an intervention used by psychologists, health care providers, and music therapists. Likewise, while the discussion here is mainly theoretical, I conclude with two possible options for better understanding eudaimonia under duress, Noddings' (2002) compassionate notion of dialogic care and Creative Industries Leadership Theory. In so doing, the article contributes to a growing body of thoughtful scholarship on the relevance of eudaimonia and music education-even in times of global peril.

\section{UNDERSTANDING EUDAIMONIA}

In the Introduction to the revised translation of Aristotle's Ethics, Barnes (1976) criticizes eudaimonia's loose interpretation to mean happiness. Though he scrutinizes happiness as too simplistic, Barnes does find some use in words like "success" and "fulfillment" as ways of explaining what eudaimonia expresses. He writes:

It will not, of course, do to replace 'happiness' by 'success' or 'fulfillment' as a translation of eudaimonia; the matter is far too complicated for any such simple remedy [...] But it is, I think, worth considering Aristotle's recipe for eudaimonia with the notion of success in mind. The Ethics, we are thus supposing, is not directly telling us how to be morally good men, or even how to be humanly happy: it is telling us how to live successful lives, how to fulfill ourselves as men. (p. 34, original emphasis)

Aristotle explains that cultivating a deeper sense of happiness is most beneficial when we share in community with others. He writes:

It is a generally accepted view that the perfect good is selfsufficient. By self-sufficient we mean not what is sufficient for oneself alone living a solitary life, but something that includes parents, wife and children, friends and fellow-citizens in general; for man is by nature a social being. (p. 74, 1097b2-21)

Here, forced isolation, one form of trauma, becomes apparent. Happiness is connected to how human beings interact with others. For the past year (as of this writing), millions of people have lived a solitary life. Extenuating circumstances made normal activities nearly impossible, less the risk of infection and even death because of coronavirus. Stepping back for a moment, consider the global impact forced isolation has on an inherently social activity such as music. The timing is right to consider how we address trauma and grief for teachers, students, and the community at large. 


\section{Eudaimonia as an Unfinished Process}

Drawing on Aristotle's (1976) writings, Waterman (1993) uses the term daimon to describe "those potentialities of each person, the realization of which represents the greatest fulfillment in living of which each is capable" (p. 678). Deci and Ryan (2008) connect eudaimonia and well-being as "not so much an outcome or end state as it is a process of fulfilling one's daimon or true nature" ( $\mathrm{p}$. 2). They emphasize the process of living the kind of meaningful life one is destined to live explaining: "the eudaimonic approach ascribes content to human nature and works to uncover that content and to understand the conditions that facilitate versus diminish it" (Deci and Ryan, 2008, p. 3). Eudaimonia is not fixed nor is it entirely complete. Waterman (1993) echoes this:

The daimon is an ideal in the sense of being an excellence, a perfection toward which one strives and, hence, it can give meaning and direction to one's life. Efforts to live in accordance with the daimon, to realize those potentials (self-realization), give rise to a condition termed eudaimonia. (p. 678)

Living with integrity, moral character, and compassion for others is never more relevant in times of peril. Music educators find much in common with Aristotle's words. Music is inherently social, and teachers commit themselves to share their love of music with students of all kinds. In doing so, many music educators aim to live in a communally-focused, eudaimonic way, or as Elliott (2020) describes: "a life that pursues ongoing selfgrowth and happiness (in the fullest sense of human flourishing) that follows from critically reflective activities" (p. 110).

It seems like good advice to tell music educators wishing to apply eudaimonic pedagogy into their praxis to start by identifying the soul-building activities lost because of the pandemic and creating space for reflection and new musicmaking modalities that embrace a similar growth-focused and healing spirit. Again, this is a misguided premise as there is no space for grief in eudaimonia's traditional conception. Honoring the self must include the mitigating circumstances that present barriers to a life well-lived. When many of those unrelenting barriers are out of the music educator's control, how do they flourish? Does flourishing matter in the midst of trying to survive (broadly defined) and suppress (emotions)?

A critical aspect of building the soul for musicians is intimacy-closeness to peers, proximity to an audience, immersion in the shared experience of music-making, and the immediacy of self-discovery while engaging in what is often a joyful, cooperative enterprise. For music educators of all kinds, inculcating an environment of soul-building is difficult in forced isolation. Certainly, the pandemic has inspired innovative ways of thinking and teaching music. A critique of the merits of inperson and online performance practice is beyond this article's scope. My point is that just as there must be space for learning musical concepts, there must also be room for educators and vested stakeholders to process and engage with what might be best described as an overnight "new normal."

Indeed, these are big, messy ideas and meant to provoke some critical reflection by the communities that encourage music educators to function in a machine-like fashion. Suppose one agrees that Aristotle's concept of a life well lived includes soulbuilding activities. In that case, a more proper eudaimonia application must consist of soul re-building and soul healingfor students, educators, and the profession. Starting that process begins by exploring the praxial conception of music education, a model informed by the ethical and socio-relational aspects of human connections.

\section{EUDAIMONIA AND SOCIAL-RELATIONAL PRAXIS IN MUSIC EDUCATION}

The social-relational aspects of eudaimonia coincide with the compassionate learning environment music educators strive to create. Music-making happens in numerous ways; encouraging students to seek excellence is essential. More fundamental to positive mentoring is fostering a more fully realized sense of self, personal growth, and lifelong learning (Elliott, 2020; Elliott and Silverman, 2014, 2015). Like music-making, Elliott and Silverman (2014) emphasize that eudaimonia "is a multidimensional term" just as educators teach "in and about music, but also through music" (p. 59, original emphasis).

Supporting Elliott and Silverman's (2015) vision of praxial music education, van der Schyff (2015) describes the ontological phenomenon of an integrated mind-body-community union "where music becomes a central way students and teachers may reengage with existence as the embodied, emotional, rational, creative, social and world-making beings they are" (p. 78).

Multidimensionality explains the natural connectedness human beings feel with others, the desire to make music in the community, and achieving synergy between the mind, body, and environment. van der Schyff et al. (2016) summarize this as the enactive perspective stating: "the enactive perspective does not conceptualize mind and cognition as distinct categories detached from the body and world" (p. 82).

Silverman (2020) uses the term personhood to explain "the importance and intricacies of all that goes into everything we say, think, believe, do, value, and create" (p. 7-8). Our sense of community, especially concerning music, helps us make sense of the world. Silverman (2020) leads us to a conception of eudaimonia by underscoring the depth of meaningfulness:

Meaningfulness takes on new dimensions when considered from 4E perspectives: it, too, is embodied embedded, enacted, and extended. Its subjective, objective, and intersubjective dimensions come about because we make it true that such reasons of love are important because of the ways in which those persons, objects, and projects connect us both to ourselves and our worlds in significant ways. (p. 8, original emphasis)

Cultivating eudaimonic pedagogy starts by acknowledging that human beings have a fundamental need to connect with others. This is much easier said than done. The pandemic shifted people from their everyday routine into forced isolation. While a detailed summary of the pandemic's impact on public health is beyond this article's scope, one cannot escape the reality that a global health crisis upends virtually every part of daily life, 
including one's relationships with loved ones, friends, colleagues, and students. Under the best of circumstances, human beings and relationships are complicated. The sudden changes brought on because of quarantines, lingering sickness, social distancing, and mask-wearing are entirely different.

Silverman (2020) explains the assortment of personal and collective possibilities in meaningfulness. If one understands that process-oriented, then it makes sense to conclude that forced isolation disrupts the normal flow of meaningfulness. Globally, the world becomes a very different place in quarantine, multiple health and financial crises, and ongoing loss. If, as Silverman (2020, p. 8) notes: "the objects and projects [that] connect us both to ourselves and our worlds in significant ways" are quickly removed, both the process of finding meaning and the meaningfulness dramatically changes for the music educator. This is not to suggest that one cannot discover new eudaimonia opportunities, but such an undertaking is not likely possible overnight. A life well-lived is precisely that-an unfinished process that evolves.

In music education, Hendricks (2018) reminds us that compassionate teaching embraces six critical themes. Teachers embody a range of qualities including trust, empathy, patience, inclusion, community, and authentic connections. More than ever, these attributes are meant to provide a safe and welcoming environment for students of all kinds. The challenge, then, is how best to support an equally nurturing environment thrust quickly upon teachers and students. Likewise, an essential foundation of stability increases the likelihood of inculcating these six areas with students (Hendricks, 2018). If one's physical and emotional space are disrupted, can they reasonably expect to flourish and stay connected in isolation? Perhaps that is one of the most unsettling parts of this discussion-analyzing the long-term effects of prolonged social distancing and instability for all musicians.

If one subscribes to the theory that educators are in a helping profession, using the term "grief" to describe the loss of close contact with students is appropriate. What about the personal connections educators have with themselves? When is it fashionable to lament the sudden removal of one's daily sense of purpose? For music educators, eudaimonia may be most apparent in the band or choir room, the private lesson studio, the music technology lab, or on the podium conducting a concert. For others, it may be accompanying young musicians on the piano, teaching aural skills, using music and movement to inspire young children, or teaching college students how to use a mixing console in the university recording studio. Is it selfish to consider that sudden upheaval and migration to online learning (and the associated stresses) has the same impact as a physical virus? Indeed, this is a figurative comparison designed to reiterate the multilayered aspects of education and eudaimonia. Prolonged distance from one's deeper vocational practice is more than a minor inconvenience, especially if physical distancing requires the practitioner to remain isolated because of inherent risk.

Bowman (2012) asks: "[Shouldn't] the practice of music education also serve the continual becoming of those who do the teaching?" (p. 2). Bowman reminds us that while pursuing a career as an educator is praiseworthy, there are many instances where teachers derive the same deep sense of purpose and pleasure as those who play an instrument. In sum, their drive for personal growth as educators is selfishly motivated. The "internal goods" that Bowman depicts coincide with the sorts of soul-building activities that Aristotle (1976) describes in Ethics. Intrinsic motivations, much like enactive and fully-realized praxis, are intricate and always visible on the surface nor are they separated from the spaces educators occupy (Bowman, 2012; Elliott and Silverman, 2014, 2015; van der Schyff, 2015; van der Schyff et al., 2016; Silverman, 2020). Bowman (2012) goes on: "There is no competition for a practice's internal goods: they are available to all who engage properly, faithfully, authentically in the practice at hand" (p. 5). In sum, immersive teaching is a pathway for deeper eudaimonic experiences.

The second trauma in music education becomes evident here. Immersive teaching generally implies an environment conducive to exchanging ideas and experiences in the music classroom or similar place. It is feasible to re-create aspects of these elements in an online course; the issue here is that the transition to online learning was hastily designed, quickly deployed, and generally viewed as a temporary solution. What's more, many institutions failed to provide adequate training, resources, and emotional support for teachers during the early parts of the coronavirus disruption. What resulted was a pedagogy of survival rather than immersive or capable of flourishing and deep satisfaction.

Bearing in mind that music educators comprise many different types, all with deeply personalized experiences, how does one logically strive for excellence if their soul aches for personal interaction with a community of music makers? Though futility is not quite an accurate description, one cannot overlook that pursuing eudaimonia will be met with skepticism by those whose lives are most impacted by the coronavirus. More so, one might make the case that striving for excellence, or pretending that everything is normal, is both dangerous and counterproductive. My point is that while technology opens up new possibilities for music-making, and some educators and students are resilient, the essence of musical eudaimonia is the soul and one's intimacy with others in the multitude of ways people experience music. When the soul aches or is remanded to quarantine, trauma occurs for a wide range of stakeholders. If such trauma is overlooked and grief ignored, finding eudaimonia is impossible. For educators, this means emphasizing survival pedagogy while stifling a redemptive, healing pedagogy. Transitioning from a survivalist mindset to a course of healing requires acknowledging that trauma exists and fostering spaces where healthy, open dialogue can occur for educators, students, and musicians.

\section{EUDAIMONIA IN A TIME OF GLOBAL TRIBULATION}

\section{Trauma-Informed Care and Therapeutic Framework}

According to van der Kolk (1994): "researchers have noted that a trauma is stored in somatic memory and expressed as changes in the biological stress response" (p. 253). A range of factors contribute to traumatic memories. For some, trauma is 
stored in the long-term memory and "researchers have noted that the psychological effects of trauma are stored in somatic memory and expressed as changes in the biological stress response" (van der Kolk, 1994, p. 253). Music and the mind are likewise interconnected. As van der Schyff (2013) points out: "the direct, embodied nature of musical experience, especially when considering music's therapeutic effects" (p. 50). Within music education, it is only recently that scholarship has moved beyond addressing trauma as merely behavioral problem or disability (Hess and Bradley, 2020).

If one builds awareness of eudaimonia's potential, a precise analysis of one's current life status is needed. Human flourishing cannot happen without first recognizing the reality of one's lived experience. Students facing quarantine, financial insecurity, disruption to routines, and lack of adequate resources experience trauma; so do teachers, colleagues, and family members. TraumaInformed Care (TIC) has roots in psychotherapy and health care; it may be useful as a framework for building awareness on how much the pandemic affected the educational community. In general, TIC seeks to build an equal, caring relationship between the provider and the client. Reeves (2015) explains: "Building trusting and egalitarian provider-patient relationships is foundational to trauma-informed practice; engaging in open communication and supporting patient autonomy can help providers and patients achieve balanced relationships" (p. 701).

The three aspects of TIC include safety, connections, and managing emotions (Bath, 2008). Citing van der Kolk and Courtois (2005), Bath (2008) writes:

It stands to reason that the treatment of children exposed to complex trauma will itself be complex and long-lasting. However, there appears to be a remarkable consensus about the key prerequisites for healing- those critical factors or therapeutic pillars that need to be in place if healing is to take place. (p. 18)

Bath refers to these factors in the context of healing childhood trauma; one might surmise that the abruptness of COVID induced new levels of trauma for music educators, artists, and students. The frailty of human existence is challenged when hundreds of thousands of people perish over the course of several months. The first step requires that people remove themselves from harm's way. Quarantining, social distancing, and wearing masks now replace normal day-to-day actions. As Bath (2008) notes, though, to fully address trauma, especially with young people, "it stands to reason, then, that the first imperative in working with traumatized [people] is creating a safe place for them" (p. 19).

Human connectivity is another aspect of TIC. Music-making is significantly affected by the absence of close interaction with peers. The abruptness of removing musicians from close contact with their peers is in itself a kind of trauma. Bath (2008) reminds us: "Although the importance of positive relationships has long been recognized, there is now good scientific evidence from human services that these are critical ingredients in healing and growth" (p. 19). There are ways of mitigating the lack of personal interaction with musical peers. However, the pandemic made any long-term planning nearly impossible, making two binary choices evident-to isolate or risk getting sick. Neither option proved ideal and emerged without much warning.

Here the theme of human interaction emerges once again. Trauma-Informed Care validates that human beings have a fundamental need to connect with others. For musicians, intimacy is a specialized expression of dialogue-represented in sundry ways including composer-to-performer, performer-toaudience, conductor-to-ensemble, and recording-to-listener.

Modeling healthy emotional behavior is the third aspect of TIC. It is important to distinguish emotional regulation because of trauma from a conformist model of classroom management. When students come to college with specific traumas, those memories leave deep emotional scars that can interfere with pursuing a eudaimonic way of living. Bath (2008) explains that young people need "adults in their lives who can understand the pervasive impact of their experiences and who recognize that the pain from ruptured connections" and those adults must "develop trauma-informed approaches that promote healing and connection" (p. 20-21). In musical parlance, students frequently emulate the behaviors they see in their private lesson teachers, conductors, accompanists, bandleaders, and mentors. If the educator has little time and space to process grief, how can they expect their students to heal? In sum, the essence of eudaimonic pedagogy is cultivating intimate spaces first for healing and then for fulfilling untapped potential.

\section{Therapeutic Framework}

A common idea expressed throughout this article is that eudaimonia, music-making, and praxis are interrelated. They are process-oriented and less concerned with a specific outcome. Eudaimonia, specifically, is concerned with fulfilling one's potential. Aristotle (1976) did not specify one isolated virtue to define the promise of fulfilling one's greater life purpose. A logical question may be to ask: Can educators, in general, fulfill a more apparent connection to the role that a caring therapist occupies in the world? To be clear, I am not suggesting that therapists and educators are the same. They both require specific sets of skills, training, experience, and credentialing. Yet, educators and therapists (broadly defined) generally aim to promote health and well-being with those they work with. In times of such global peril, educators have been forced into multiple roles-that of caretaker, teacher, technology expert, and counselor.

With reflective implementation, can educators adopt a therapeutic perspective on their work, especially when addressing student trauma? Perret (2005) leads us to a more concrete understanding of therapy, pedagogy, personal development and healing from the lens of music therapy:

We can define as therapeutic all work that aims to help a person overcome a pathology, an illness or a strong crisis, whereas pedagogical work is concerned to help a person who is in 'good health' (mentally and physically) to develop her skills further. We can designate as personal development all work on oneself designed to help one's spiritual potential or one's innate qualities. I feel strongly that all these activities should be placed along the same line whose middle point would mark a hypothetical state called "well-being" (p. 138). 
Though they are not one in the same, music therapy and music education share some commonalities with eudaimonia. The question is how the music educator cultivates an awareness of their innate capacity to care for others while attending to both personal well-being and that of their students. If the consensus is that eudaimonia is process-driven, then it means that educators can learn how to connect with it over time to use for a healing pedagogy.

Undertaking what might be referred to as an evolving Trauma-Informed Pedagogy of Care begins with a recognition and validation that many aspects of music-making remain upended by unpredictable circumstances, along with validating the loss many educators still experience. To advance this compassionate praxis model, educators need resources to deal with their grief before attempting to heal others. To use an analogy from flying, one must put on their oxygen mask before helping others. To accomplish that task, their lack of oxygen and resources requires acknowledgment. If there are lingering effects from a lack of oxygen, replacing the mask is not a sufficient remedy. The survivor may need a range of holistic solutions to help them move forward in life.

\section{MOVING TO A PHILOSOPHY AND PRAXIS OF CARE}

Noddings (2002) states: "Character education has its roots in virtue ethics and recognizes Aristotle as its progenitor" ( $p$. 2). What does it mean to connect eudaimonia and grief in an educational setting? The root of this concept lies in what Noddings (1992) refers to as:

[Caring] relation, [which] is, in its most basic form, a connection or encounter between two human beings-a carer and a recipient of care, or cared for. In order for the relation to be properly called caring, both parties must contribute to it in characteristic ways. (p. 15)

Neither formulaic nor feasible as a one-sided relationship, Noddings (1992) reminds us that: "no matter how hard teachers try to care, if the caring is not received by the students, the claim that 'they don't care' has some validity (p. 15). As an alternative, Noddings (2002) argues that "as teachers, we are far more likely to concentrate on establishing conditions that will call forth the best in students, that will make being good both possible and desirable" (p. 2). Elsewhere, Noddings (1995) describes the innate human tendency to respond to another person's problem as "natural caring... [where] the motive to care arises on its own; it does not have to be summoned" (p. 187). In times of great tragedy, it is not uncommon for others to donate funds or services to help their communities. Much like critical pedagogy and music-making, understanding the philosophy of care must consider the environment where people live.

Another aspect of care that Noddings describes is "ethical caring," or more loosely defined as the "ought to" form of caring (p. 187). She alludes to the inner dialogue that people have in knowing the good of caring for others but not feeling immediately motivated to take action. To overcome this barrier,
Noddings (1995) encourages educators to recall instances where they were cared for, in whatever capacity. She states: "Ethical caring's great contribution is to guide action long enough for caring to be restored and for people once again to interact with mutual and spontaneous regard" (Noddings, 1995, p. 187). Again, caring is a process rather than an arrival at a specific outcome. When educators acknowledge their humanity and take steps to care for others, they are likely to evolve closer to a constant state of care.

However, the issue is that caring, and moral education in general, must acknowledge that "virtues are defined situationally and relationally" (Noddings, 2002, p. 2). Since early 2020, the space and place where people occupy their time have dramatically changed. So too have the ways that people communicate with each other. Using web-conferencing (ex: Zoom, FaceTime, Skype) helps maintain some semblance of routine and contact with others; it does not replace the close personal interactions an educator has with her students in the classroom-even more so for music educators working with students in rehearsals, ensembles, recording sessions, and outside the school informally. Noddings (2002) describes dialogue as a crucial part of caring and moral education.

Noddings (2002) makes a critical observation:

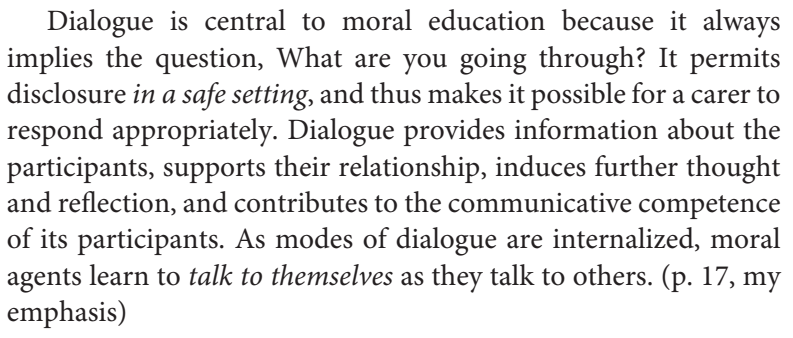

A dialogue takes on two essential roles. First, it invites both parties (the carer and cared-for) to express vulnerability when appropriate. Unlike small-talk or casual conversation, the dialogue is substantive. It is intentional and requires attention and tact. Dialogue moves the spoken relationship toward reciprocity and listening. When one person shares personal details, the other person may be likely to follow in response. Vulnerability is not guaranteed, but like other concepts articulated in this article, a dialogue is a process. Noddings (2002) makes clear that people can learn to dialogue with each other. Understandably, shifting an entire course into a distance learning mode within days is a daunting task because of the pandemic. The kind of dialogue inspired in the online realm is likely different than the ongoing relationships built in a classroom.

Noddings (2002) reminds us that healthy dialogue requires a specialized type of emotional comportment. Meaningful dialogue engages both parties to listen intently and engage with the other person beyond a trivial conversation. For caring educators, inner-dialogue, a conscience leading to ethical decision-making, requires space, support, and validation. During times of physical and emotional upheaval, creating space for the inner dialogue proves difficult. Removing the daily connections with students and colleagues, increases separation anxiety and external validation opportunities, a crucial element of a two-way 
conversation with the teacher and student, the teacher and colleague, and the teacher with herself.

As with the other scenarios explored in this article, Noddings' dialogic care model cannot happen in a vacuum. Human beings are social. Music is a social activity for many. Conversations, musical or otherwise, require at least two parties to participate. Correspondingly, for ethical models of teaching and learning to grow, there must be a safe element to evaluate the process. For most music educators, this means being near students where the sounds and experiences of music-making happen. So long as there is a disconnect in the opportunities for personalized connection between the teacher and student and the teacher and their inner-self, the survivalist pedagogy will remain.

\section{MOVING AHEAD: RECOMMENDATIONS FOR A EUDAIMONIC PEDAGOGY}

\section{Creative Industries Leadership}

There is still so much unknown about the protracted effects of COVID-19 on higher education, musicians, the arts, teachers, and students. As the casualties continue to rise, unemployment figures and lost revenues leave people with prolonged financial insecurity, and general pandemic fatigue set in, a shift by educators to leadership, healing, and respect becomes all the more urgent. Eudaimonic pedagogy is a healing-focused process.

In Walzer (2020), I presented a theory called Creative Industries Leadership (CIL). The primary focus of CIL is to generate a shared, collective vision for stakeholders navigating an uncertain future in the arts and education sectors. Two aspects of CIL emphasize Community and Sustainability. If there is to be a transition to human flourishing in the music world, educators must accept the responsibility to interrogate the systems that limit the scope of healthy and cooperative music-making. CIL theory aims to build communities designed to share resources and pool knowledge. In Walzer (2020) I explain this:

[A] benefit of the Creative Industry Leadership theory is that it recognizes knowledge and aims to share that expertise for the common good. This equates to building communities of thinkers and doers aimed at steadying the course of an uncertain future. Much like strategic investing, the goal is to develop a steady growth plan. (p. 166)

Indeed, this is not the same thing as investing in a business. What I propose is that educators focus more on healing themselves and investing in the concepts outlined earlierdialogue, promoting safe spaces (online and offline), embracing creativity, acknowledging grief, and patiently working on a process of healing. One might view CIL as a clarion call to emphasize healing such that the arts can 1 day flourish again. Finding space to view music-making and teaching as a healing and therapeutic process brings the pedagogy closer to eudaimonia. The Sustainability aspect of CIL views the entire enterprise of education as a lifelong endeavor entirely deserving of commitment and emotional energy (Walzer, 2020).

Equally important to the discussion of moving ahead is reevaluating how we define subjective terms like "excellence" and "flourishing" when all directions point to stagnation, isolation, and deep loss during times of stress. If one subscribes to the idea that music promotes soul-building and healing, why do we not view educators in the same light? Critics of the arts are quick to cut funding and expect those in the trenches to more with less. Even more concerning is the idea that music educators must go along to get along. One cannot have it both ways. If music is good for the soul, then the souls of the providers need space to heal and process.

\section{CONCLUSION}

The future of the creative industries remains precarious. Educators working closely with students face ongoing challenges to fulfill multiple roles while finding space to address their present circumstances. If the educational community agrees that eudaimonic pedagogy is process-oriented rather than resultsdriven, then the focus shifts from "traditional" models of music-making to a trauma-informed, critically aware praxis that acknowledges the ongoing trauma that arts professions face at this moment. Likewise, finding one's lifelong purpose is mainly subjective and generally not apparent in times of extreme duress. This is not to suggest that eudaimonia is a futile exercise; instead, the timing is right to recognize that music educators are fundamentally compassionate, creative, and committed to their students. It is only in recognizing the grief and trauma of loss that eudaimonia can emerge as a newly- inspired and healing-focused pedagogical model in music education in the coming years.

Throughout this article, I have argued for a new conception of eudaimonic pedagogy. The essence of this theory is that human beings need each other. For music to flourish in general, there is strength in numbers. One cannot blame educational institutions or human beings for going into survival mode in stressful times. Yet, if the music education profession is to grow, then there must be room for discussion of humanity. Grief, humane interventions, and validation are part and parcel of the therapy and healing process. Unlocking those elements will make music education a more deeply empathetic and meaningful profession-particularly for those on the front lines working with students ethically, compassionately, and with love.

\section{DATA AVAILABILITY STATEMENT}

The raw data supporting the conclusions of this article will be made available by the authors, without undue reservation.

\section{AUTHOR CONTRIBUTIONS}

DW contributed the entirety of original research and scholarship.

\section{FUNDING}

Funding for OA charges is provided by research startup funds from IUPUI's Music and Arts Technology Research Startup. 


\section{REFERENCES}

Aristotle (1976). Ethics (Rev. Translation by H. Tredennick). London: Penguin Books.

Barnes, J. (1976). "Introduction," in Aristotle's Ethics ed H. Tredennick trans. (London: Penguin Books).

Bath, H. (2008). The three pillars of trauma-informed care. Reclaim. Children Youth 17, 17-21.

Bowman, W. (2012). Practices, virtue ethics, and music education. Action Criticism Theory Music Educ. 11, 1-19.

Deci, E. L., and Ryan, R. M. (2008). Hedonia, eudaimonia, and well-being: an introduction. J. Happiness Stud. 9, 1-11. doi: 10.1007/s10902-006-9018-1

Elliott, D. J. (2020). "Eudaimonia and well-doing," in Eudaimonia: Perspectives for Music Learning, eds G. Smith and M. Silverman (New York, NY: Routledge).doi: 10.4324/9780429264948-9

Elliott, D. J., and Silverman, M. (2014). Music, personhood, and eudaimonia: implications for educative and ethical music education. TD: J. Transdiscip. Res. South. Afr. 10, 57-72. doi: 10.4102/td.v10i2.99

Elliott, D. J., and Silverman, M. (2015). Music Matters: A Philosophy of Music Education, 2nd Edn. Oxford: Oxford University Press.

Grover, N. (2020). "Nearly One in Five Covid Patients Later Diagnosed with Mental Illness - Study." The Guardian. Available online at: https:/www.theguardian.com/world/2020/nov/10/nearly-one-in-five-covidpatients-later-diagnosed-with-mental-illness-study. (accessed November 22, 2020)

Hendricks, K. S. (2018). Compassionate Music Teaching: A Framework for Motivation and Engagement in the 21st Century. Lanham, MD: Rowman \& Littlefield.

Hess, J., and Bradley, D. (2020). Dewey's theory of experience, traumatic memory, and music education. Stud. Philosophy Educ. 39, 429-446. doi: 10.1007/s11217020-09706-z

Kincheloe, J. (2008). Critical Pedagogy: A Primer, 2nd Edn. New York, NY: Peter Lang Publishers. doi: 10.1007/978-1-4020-8224-5

Noddings, N. (1992). The Challenge to Care in Schools: An Alternative Approach to Education. New York, NY: Teachers College/Columbia University Press.

Noddings, N. (1995). Philosophy of Education. Oxford: Westview Press.

Noddings, N. (2002). Educating Moral People: A Caring Alternative to Character Education. New York, NY: Teachers College/Columbia University Press.

Perret, D. (2005). Roots of Musicality: Music Therapy and Personal Development. London: Jessica Kingsley Publishers.

Reeves, E. (2015). A Synthesis of the Literature on Trauma-Informed Care. Issues Ment. Health Nurs. 36, 698-709. doi: 10.3109/01612840.2015.1025319
Rothschild, P. C., Vowels, K. A., and Rothschild, C. L. (2020). "Cancel, postpone, or reschedule: the live music industry's response to ticket refunds during the COVID-19 Pandemic. J. Music Entertain. Industr. Educ. Assoc. 20, 45-83. doi: $10.25101 / 20.2$

Silverman, M. (2020). Sense-Making, meaningfulness, and instrumental music education. Front. Psychol. 11:837. doi: 10.3389/fpsyg.2020.00837/full

Smith, G. D. (2020). "Yeah, we all here tryna flourish": a reflection on a symposium on eudaimonia and music learning. Int. J. Multidisciplin. Perspect. Higher Educ. 5, 119-129. doi: 10.32674/jimphe.v5i1.2510

Smith, G. D., and Silverman, M. (eds) (2020). Eudaimonia: Perspectives for Music Learning. New York, NY: Routledge. doi: 10.4324/9780429264948

van der Kolk, B. A. (1994). The body keeps the score: memory and the evolving psychobiology of posttraumatic stress. Harvard Rev. Psychiatry 1, 253-265. doi: 10.3109/10673229409017088

van der Kolk, B. A., and Courtois, C. A. (eds) (2005). Editorial comments: complex developmental trauma. J. Traumatic Stress 18, 385-388. doi: 10.1002/jts. 20046

van der Schyff, D. (2013). Emotion, embodied mind and the therapeutic aspects of musical experience in everyday life. Approaches: Music Ther. Special Music Educ. 5, 50-58.

van der Schyff, D. (2015). Praxial music education and the ontological perspective: an enactivist response to music matters 2. Action Criticism Theory Music Educ. 14, 75-105.

van der Schyff, D., Schiavio, A., and Elliott, D. J. (2016). Critical ontology for an enactive music pedagogy. Action Criticism Theory Music Educ. 15, 81-121. doi: $10.22176 /$ act15.5.81

Walzer, D. (2020). Leadership in the creative industries: addressing an uncertain future. J. Music Entertain. Educ. Assoc. 20, 147-172. doi: 10.25101/20.5

Waterman, A. S. (1993). Two conceptions of happiness: contrasts of personal expressiveness (Eudaimonia) and hedonic enjoyment. J. Personal. Soc. Psychol. 64, 678-691. doi: 10.1037/0022-3514.64.4.678

Conflict of Interest: The author declares that the research was conducted in the absence of any commercial or financial relationships that could be construed as a potential conflict of interest.

Copyright (C) 2021 Walzer. This is an open-access article distributed under the terms of the Creative Commons Attribution License (CC BY). The use, distribution or reproduction in other forums is permitted, provided the original author(s) and the copyright owner(s) are credited and that the original publication in this journal is cited, in accordance with accepted academic practice. No use, distribution or reproduction is permitted which does not comply with these terms. 